Preface

\section{A Short History of Thrombosis and Hemostasis: Part II (40th Year Celebratory Issue)}

\author{
Emmanuel J. Favaloro, PhD, FFSc (RCPA) ${ }^{1}$ \\ 1 Department of Haematology, Institute of Clinical Pathology and \\ Medical Research (ICPMR), Westmead Hospital, Westmead, Australia
}

Semin Thromb Hemost 2014;40:826-830.
Welcome to a very special issue of Seminars in Thrombosis \& Hemostasis, the second of two-planned issue compilations that revolve around the history of thrombosis and hemostasis research, and specifically aiming to celebrate the 40th anniversary of this journal. Seminars in Thrombosis \& Hemostasis began its life in 1974, and thus 2014 marks its 40th anniversary in press. The founding editor of Seminars in Thrombosis $\mathcal{E}$ Hemostasis, Eberhard F. Mammen, passed away in 2008, as announced in this journal at that time, ${ }^{1-3}$ and as also marked then with a special issue aimed to celebrate his life and contribution to this field. ${ }^{4}$ Of special note, the previous 40th anniversary issue of the journal ${ }^{5}$ also contained several tributes to Eberhard Mammen.

Some interesting statistics regarding Seminars in Thrombosis \& Hemostasis that we highlighted in the first issue, ${ }^{5}$ I will again summarize for the interested reader. The journal began publishing in 1974 with just two issues per year, for a grand total of 210 pages published in that year. This grew to four issues, with a total of 408 pages in the next year. The journal continued to publish four issues per year for the next two decades, with an average of approximately 400 pages, plus the occasional supplement, until 1996, when it grew to six issues per year. Seminars in Thrombosis $\mathcal{E}$ Hemostasis then published an average of just over 600 pages in six issues per year for the next decade until 2006, when it again grew, this time to eight issues per year. The year 2006 also brought marked change as the Journal began a new life with a revamped and extended Editorial Board (including me!) and the start of geographically based "Regional Editors"-a system that later transitioned into "Senior Editors." The journal has continued to publish eight issues per year, with an average of nearly 900 pages per year from that time. In the previous year, 2013, we published 973 pages of text. In the year 2014, we will not yet break the 1,000-page barrier, but the sustained growth of the journal as well as the literature surrounding Thrombosis and Hemostasis indicates this to be only a matter of time. These data are summarized in - Fig. 1.

We begin this celebratory issue with several con-

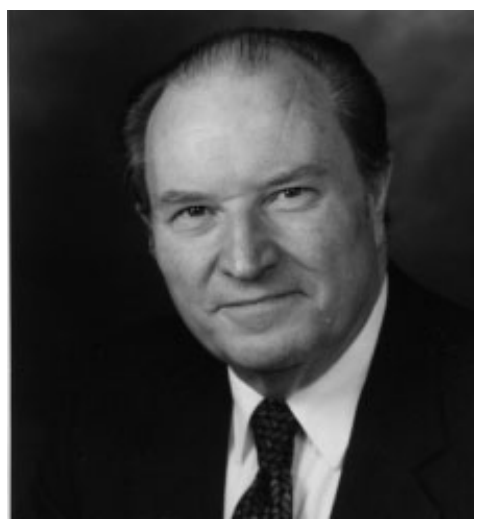

Eberhard F. Mammen (1930-2008), Founding Editor, Seminars in Thrombosis \& Hemostasis. tributions around the theme of the "old and the new" in anticoagulant therapy. The first contribution, by Harenberg et $\mathrm{al}^{6}{ }^{6}$ is on the anticoagulant and nonanticoagulant actions of glycosaminoglycans, a family of compounds that includes heparin. Heparin was originally discovered in the beginning of the 20th century and was initially identified as a "procoagulant" isolated from liver tissue. Only later did its true nature as an anticoagulant become recognized, paving the way to its first application in patients approximately 30 years after its discovery. Further purification of heparin identified the major as well as minor, but important, component units of the complex chain mixtures that constituted heparin, and subsequently, the multiplex actions of this compound slowly evolved. As detailed by the authors, this evolution of knowledge was disseminated and shared in a series of "Glycosaminoglycan symposiumanticoagulant and nonanticoagulant actions" held over the past 20 years and which published research arising within several issues of Seminars of Thrombosis \& Hemostasis as well as in other international scientific journals. Summarized in this overview are the latest developments of methods of their analysis, of their synthesis, their degradation by heparinases, and their nonanticoagulant effects in tumor growth, in antiinflammatory diseases, and in Alzheimer diseases, as presented at the last (21st) symposium, and on the occasion of the 40th anniversary of the journal, with special reference to the journal's founding Editor-in-Chief, Eberhard Mammen.

Continuing the exploration of the old and the new in heparin and related molecules is the contribution by Lassila and Jouppila on mast-cell-derived heparin proteoglycans as a model for a local antithrombotic. ${ }^{7}$ These authors, in part,
Copyright @ 2014 by Thieme Medical Publishers, Inc., 333 Seventh Avenue, New York, NY 10001, USA. Tel: +1(212) 584-4662.
DOI http://dx.doi.org/ 10.1055/s-0034-1395164. ISSN 0094-6176.
(RCPA), Department of

Haematology, Institute of Clinical

Pathology and Medical Research (ICPMR), Westmead Hospital,

Westmead, Australia (e-

mail: emmanuel.favaloro@health. nsw.gov.au).
Issue Theme A Short History of II (40th Year Celebratory Issue); Guest Editor: Emmanuel J.

Favaloro, PhD, FFSc (RCPA). 


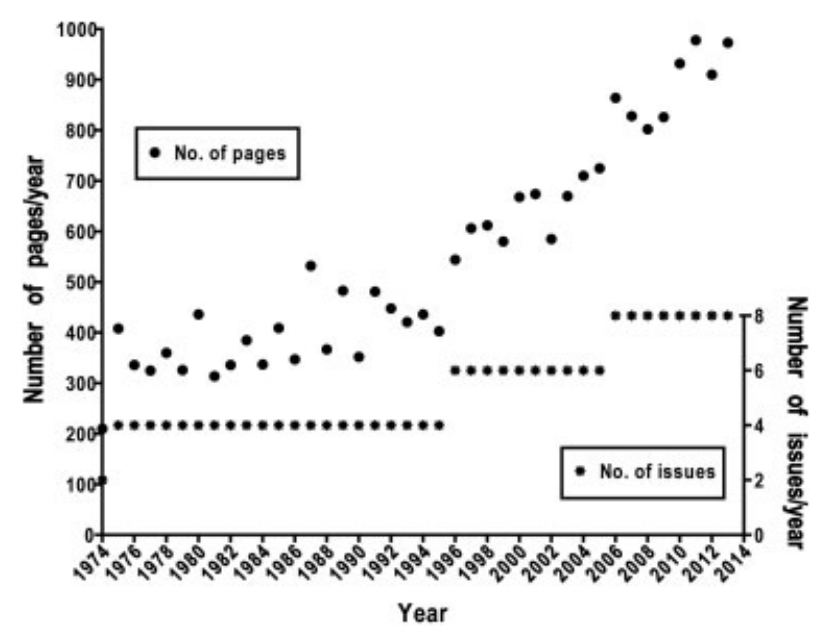

Fig. 1 Seminars in Thrombosis \& Hemostasis: number of issues/year and number of printed pages/year, from its birth in 1974 until 2013. In the year 2014, we will not break the 1,000-page barrier.

reflect on a similar historical perspective to the first contribution. ${ }^{6}$ Heparin, as currently used clinically, is isolated from its protein backbone from porcine and bovine gut mucosa. The isolated heparin is an anticoagulant; however, when bound to a protein carrier, the heparin conjugates will become antiplatelet agents by inhibiting collagen-induced platelet aggregation and procoagulant activity, actions that are distinct from soluble heparin. Mast cell-derived heparin proteoglycans (HEP-PG) reside in vascular tissue and can serve as a local antithrombotic. HEP-PG, whether soluble or immobilized to a surface, inhibit platelet deposition on collagen surface in flowing blood. Mimics of HEP-PG, termed APACs (anti-platelet anti-coagulants) by the authors, can be tailored to carry both antiplatelet and anticoagulant properties. These molecules can target the vascular injury site and there take residence. Inhibition of thrombus growth using these APACs under these conditions has been demonstrated in several animal models. Although apparently efficacious for antiplatelet and anticoagulant effects, the bleeding time is significantly shorter with APACs than with unfractionated heparin, therefore, suggestive of an improved safety profile. The strategies outlined by these authors may therefore be useful in future drug development, where many vascular injury-related problems can be tackled by local application of tailored drugs.

The third contribution for this issue discusses a topic related in part to another major form of anticoagulant therapy, namely vitamin $\mathrm{K}$ antagonist (VKA) therapy such as warfarin. ${ }^{8}$ To be truthful, VKA therapy is not the main topic of this contribution and is mainly used to provide some historical context to the main topic of discussion, being the derivation of the international normalized ratio (INR), currently used to harmonize the prothrombin time and to monitor VKA therapy, and now increasingly used as a major laboratory variable in calculating the widely used Model for End-Stage Liver Disease (MELD) score for liver transplant organ prioritization. Gatt et al remind us how the use of the INR has greatly improved the safety and effectiveness of
VKA therapy. However, as the conventional INR (INR $\mathrm{VKA}_{\mathrm{VA}}$ ) is calibrated specifically for VKA patients, its interlaboratory variation has a significant and potentially adverse impact on the accuracy of the MELD score. Although still requiring further clinical validation in large numbers of waitlisted patients, the alternative "liver INR" ( INR $\left._{\text {liver }}\right)$, calibrated by using plasma from liver disease patients instead of VKA patients, may harmonize the differences better and thus be better suited for MELD score calculation. The overall objective of this article is to review the history of INR, MELD score, and $I N R_{\text {liver }}$, and to further discuss the challenges and solutions of $\mathrm{INR}_{\text {liver }}$ implementation.

The fourth contribution in this issue of Seminars of Thrombosis $\mathcal{E}$ Hemostasis reflects the last specifically directed to anticoagulant therapy, and this time on the newer direct oral anticoagulants. ${ }^{9}$ Originally defined as new or novel oral anticoagulants (NOACs), and later (as they became not so new or novel) as direct oral anticoagulants (DOACs), Suryanarayan and Schulman refer to them as non-VKA oral anticoagulants, permitting reuse of the original abbreviation (NOAC), and following a convention agreed on by a group of experts in the field. ${ }^{10}$ For patients taking VKA anticoagulants, poor adherence to the prescribed drug regimen is associated with a lower percent time in the therapeutic range and also with an increased risk of thromboembolic complications. The NOACs do not require routine laboratory monitoring and therefore pose some risk for clinical nondetection of the patient's nonadherence, and thus any potential clinical intervention to attempt corrective action to improve adherence becomes challenging. Persistence with NOAC and VKA therapy was quite comparable in the phase III trials, whereas a postmarketing study demonstrated better persistence with dabigatran than with warfarin. Preliminary studies on adherence to the dabigatran regimen have shown poor adherence in 12 to $27 \%$ of patients, and such behavior seems associated with unfavorable outcomes akin to poor adherence with VKA therapy. There is uncertainty about the best methods to evaluate adherence, and studies on adherence are required for all NOACs, including different clinical settings and patient populations. Unlike the case for VKA, where regular monitoring and a comparatively longer half-life provides a better handle for evaluating adherence, the short half-life of the NOACs challenge assessment of adherence using laboratory testing. ${ }^{11}$ The authors therefore propose that a combination of strategies should probably be used to achieve the best possible adherence, including patient education and some form of automatic reminders.

To highlight the importance of anticoagulant therapy to the topic of thrombosis and hemostasis, and to also provide some additional historical context to the theme explored in the first four contributions to this issue, we have included in the Appendix of this issue a reproduction of a paper published in this journal nearly 40 years ago, on guidelines for the management of anticoagulant therapy. ${ }^{12}$ At that time, the therapeutic options were heparin and VKA therapy. Despite this article now being nearly 40 years in press, these guidelines are to some extent still relevant. Although we have learnt much about these drugs in the intervening years, 
heparin and VKA therapy anticoagulation is still employed today, and despite the increasing usage of the newer anticoagulants, ${ }^{9-11}$ both heparin and VKA therapy look likely to continue to be used in many patients for several indications for many years still to come. ${ }^{1-3,11}$

This issue of the journal then turns its attention to various hemostatic disorders. The first of these contributions is by Pengo et al who discuss the history of lupus anticoagulant (LA). ${ }^{13}$ LA represents one representation of antiphospholipid antibodies (aPL), which are used to identify the antiphospholipid syndrome (APS), a prothrombotic autoimmune disorder characterized by many different clinical presentations. ${ }^{14}$ LA as a term actually represents a double misnomer, as these neither characterize the clinical condition of systemic lupus erythematosus (SLE) nor reflect in vivo anticoagulants. The history of LA dates back at least 50 years, when a unique coagulation inhibitor prolonging whole-blood clotting time was described in two patients with SLE, helping to explain the use of the descriptor "lupus" anticoagulant. The immunoglobulin nature of the inhibitor and its interaction with anionic phospholipids was later demonstrated and the term "lupus anticoagulant" was coined to describe the laboratory finding. It later became recognized that LA was a misnomer as LA is more often found in plasma from patients with clinical conditions other than SLE, and LA is associated with thromboembolic events that may occur in otherwise healthy individuals. Individuals with LA have circulating autoantibodies that interfere with blood coagulation-in vitro this action appears as "anticoagulant" in nature, whereas in vivo, these autoantibodies are actually prothrombotic. These LA associated aPL are mostly of IgG or IgM class and mainly directed against a (PL)-binding plasma protein, $\beta 2$-glycoprotein I $(\beta 2 \mathrm{GPI})$. The presence of $\beta 2 \mathrm{GPI}-d e p e n d e n t \mathrm{LA}$ represents a well-recognized risk factor for venous and arterial thromboembolism, as well as pregnancy loss and morbidity. $\beta 2 \mathrm{GPI}-$ dependent LA in the presence of documented previous thromboembolism, or history of pregnancy loss/morbidity, identifies definite APS. Laboratory diagnosis of LA is thus of particular importance, as it may assign patients with a common event (thrombosis) to a group with a high risk for recurrence, which is a prerequisite for long-term oral antithrombotic treatment.

As a belated dedication to a former pioneer in the area of LA testing, we have reproduced in the Appendix an article on LA by Douglass A. Triplett, ${ }^{15}$ who passed away in 2013 at the too young age of 69 years. ${ }^{16}$

The next contribution, by Wada et al is on the various thrombotic microangiopathies (TMA) including thrombotic thrombocytopenic purpura (TTP) and hemolytic uremic syndrome (HUS), ${ }^{17}$ and representing other forms of prothrombotic disorders. Seminars of Thrombosis $\mathcal{E}$ Hemostasis has published two recent issues on this topic, ${ }^{18,19}$ and the authors of the current contribution provide an overview of the history and current aspects of these clinically significant disorders. The authors propose that the differential diagnosis of TMA has become clearer following the establishment of the relationships between (1) diarrhea-associated HUS and Shiga toxin-producing Escherichia coli-HUS (STEC-HUS), (2) a markedly reduced ADAMTS-13 (a disintegrin and metalloproteinase with a thrombospondin type 1 motif, member 13) level and typical TTP, and (3) abnormalities in the complement regulatory system and atypical HUS (aHUS). Nevertheless, the pathological mechanisms of TMA still overlap among several forms of TMA. With respect to the management of TMA, the use of plasma exchange for typical TTP, additional steroid therapy for TMA and rituximab for typical TTP with a high titer of the inhibitor of ADAMTS-13, as well as eculizumab for aHUS, have also been established. Although several issues remain in the pathophysiology and management of TMA, the authors reflect that the new findings should resolve these problems in the near future.

The next contribution is on the subject of disseminated intravascular coagulation (DIC) and has been provided by a senior editor of Seminars in Thrombosis \& Hemostasis, Marcel Levi, and his colleague, Tom van der Poll. ${ }^{20} \mathrm{DIC}$ is a syndrome characterized by systemic intravascular activation of coagulation, leading to widespread deposition of fibrin in the circulation. There is ample experimental and pathological evidence that the fibrin deposition contributes to multiple organ failure. The massive and ongoing activation of coagulation may result in depletion of platelets and coagulation factors, which may cause bleeding (consumption coagulopathy). The syndrome of DIC is well known in the medical literature, dating back centuries, although a more precise description of the underlying mechanisms was originally proposed in the 20th century. Initial ideas on a role of the contact activation system as the primary trigger for the systemic activation of coagulation as well as a presumed hyperfibrinolytic response in DIC have been found to be misconceptions. Experimental and clinical evidence instead indicate that the initiation of coagulation in DIC is caused by tissue factor expression, which in combination with downregulated physiological anticoagulant pathways and impaired fibrinolysis leads to widespread fibrin deposition. In addition, an extensive bidirectional interaction between coagulation and inflammation may further contribute to the pathogenesis of DIC.

This contribution provides us with an opportunity to reproduce in the Appendix of this issue an earlier work on DIC by a great past supporter of the journal, Rodger L. Bick. ${ }^{21}$ It is interesting that this article carries its own historical treatment of the topic. Dr. Bick passed away in 2008, ${ }^{22,23}$ but he contributed to 34 articles published in Seminars in Thrombosis \& Hemostasis during the period 1976 to 2004, a time span of almost three decades.

Next in line for the issue is a contribution by Ellery and Adams on tissue factor pathway inhibitor (TFPI), the major physiological regulator of tissue factor (TF)-induced blood coagulation. ${ }^{24}$ It is now generally accepted that the TF-driven hemostasis system has more physiological and pathophysiological hemostasis-related relevance than the contact pathway, helping in part to explain why deficiencies in contact factors including factor XII do not lead to a bleeding diathesis. TFPI inhibits the TF-activated factor VII (FVIIa) complex in an activated factor X (FXa)-dependent manner, helping to control thrombin generation and ultimately fibrin formation. The 
importance of TFPI is demonstrated in models of hemophilia where lower levels of factor VIII or IX are insufficient to overcome its inhibitory effect, resulting in a bleeding phenotype. There are two major isoforms in vivo. TFPI $\alpha$ contains three Kunitz-type inhibitory domains (designated K1, K2, and $\mathrm{K} 3$ ), is secreted by endothelial cells and requires protein $\mathrm{S}$ to enhance its anticoagulant activity. In contrast, TFPI $\beta$ contains only the $\mathrm{K} 1$ and $\mathrm{K} 2$ domains, but it is attached to the endothelial surface via a glycosylphosphatidylinositol anchor. This review provides a brief history of the major discoveries related to TFPI, and also discusses new insights into the physiology of TFPI, including updates on its association with protein $\mathrm{S}$ and factor $\mathrm{V}$, as well as the current understanding of its association with disease.

The next contribution by de Maat and colleagues is a fitting partner to the former contribution, and discusses contact system activation in endothelial cells. ${ }^{25}$ When the contact system assembles and activates on negatively charged surface materials, plasma coagulation rapidly follows. Although this mechanism is largely redundant for hemostasis, it nonetheless mediates pathological thrombus formation as has been reported in a multitude of in vivo studies. The epidemiological data are presently scarce to firmly support a role for the contact system in human thrombotic disease, whereas its physiological function and mode of activation remain largely unclear. Besides its role in blood coagulation in vitro, the contact system is responsible for the production of bradykinin. This inflammatory peptide is involved in episodes of pathological tissue swelling in (hereditary) angioedema, but potentially it is also involved in the physiological regulation of vascular permeability. A body of evidence indicates that contact system factors are recruited to the surface of activated endothelial cells, where proteins that are locally released can activate them. Furthermore, clinical and biochemical studies indicate that plasmin, the effector enzyme of the fibrinolytic system, can evoke contact system activation. This auxiliary role for plasmin may so far not have been fully appreciated in pathophysiology. In conclusion, the authors propose a complementary model for contact system activation on the endothelial cell surface that is initiated by plasmin activity.

This issue of Seminars in Thrombosis $\mathcal{E}$ Hemostasis concludes with the contribution by Oldenburg et al, ${ }^{26}$ with a historical look at genetic analysis in hemophilia A. Molecular genetic analysis is now widely applied in the investigation of inherited bleeding disorders. For hemophilia, the outcome of genetic analysis allows genetic counselling in affected families and helps to find a link between the genotype and phenotype. Genetic analysis in hemophilia A has improved considerably in the past few decades. Many new techniques and modifications as well as analysis software have become available; these have enabled genetic analysis and interpretation of data to become faster and more accurate. The advances in mutation detection strategies now facilitate the identification of the causal mutation in up to $97 \%$ of patients with hemophilia $A$. The authors review the milestones in genetic analysis of hemophilia A and highlight the importance of identification of the causative mutations for genetic counseling, and particularly, for the interpretation of the clinical presentation of the affected patients.

As always, I thank all the authors to this issue of Seminars in Thrombosis \& Hemostasis for their original and comprehensive contributions. In this issue, several contributions have come from members of the editorial board, and I am grateful for their assistance in celebrating the past achievements in the fields of thrombosis and hemostasis. Finally, as noted in the separate dedication to this issue of Seminars in Thrombosis $\mathcal{E}$ Hemostasis, I am sure that past pioneers and mentors in the field will have the unending gratitude of the entire thrombosis/hemostasis research community.

I hope that the readership of this journal finds the entire issue of considerable interest, and I look forward to the next 40 years of the history of thrombosis and hemostasis to be presented in this journal.

\section{References}

1 Schiff D. Eulogy. Eberhard Mammen, M.D. 1930-2008. Semin Thromb Hemost 2008;34:305

2 Prasad A, Kwaan HC. In memoriam: a tribute to Eberhard F Mammen, M.D. (1930-2008). Semin Thromb Hemost 2008;34: 697-698

3 Fareed J, Walenga JM, Hoppensteadt DA, Bick RL, Messmore HL. Dr Eberhard F Mammen remembered: a great clinician-scientist, mentor, and friend. Semin Thromb Hemost 2008;34:128-130

4 Favaloro EJ. A tribute to Eberhard F. Mammen, M.D. (1930-2008). Semin Thromb Hemost 2008;34(8):703-707

5 Favaloro EJ. A short history of thrombosis and hemostasis: part I (40th year celebratory issue). Semin Thromb Hemost 2014;40(5): 521-525

6 Harenberg J, Casu B, Krämer R, Torri G, Naggi A, Krämer S. Glycosaminoglycans: anticoagulant and nonanticoagulant actions: a short history of symposia held at Villa Vigoni. Semin Thromb Hemost 2014;40(8):831-836

7 Lassila R, Jouppila A. Mast-cell derived heparin proteoglycans as a model for a local antithrombotic. Semin Thromb Hemost 2014; 40(8):837-844

8 Gatt A, Chen D, Pruthi RK, et al. From vitamin $k$ antagonists to liver international normalized ratio: a historical journey and critical perspective. Semin Thromb Hemost 2014;40(8):845-851

9 Suryanarayan D, Schulman S. When the rubber meets the road: adherence and persistence with non-vitamin K antagonist oral anticoagulants and old oral anticoagulants in the real world-a problem or myth? Semin Thromb Hemost 2014;40(8): 852-859

10 Husted S, de Caterina R, Andreotti F, et al; ESC Working Group on Thrombosis Task Force on Anticoagulants in Heart Disease. Nonvitamin $\mathrm{K}$ antagonist oral anticoagulants (NOACs): No longer new or novel. Thromb Haemost 2014;111(5):781-782

11 Lippi G, Favaloro EJ. Recent guidelines and recommendations for laboratory assessment of the direct oral anticoagulants (DOACs): Is there consensus? Clin Chem Lab Med 2014; DOI: 10.1515/cclm2014-0767

12 Gurewich V. Guidelines for the management of anticoagulant therapy. Semin Thromb Hemost 1976;2(3):176-196

13 Pengo V, Bison E, Denas G, Jose SP, Bracco A, Banzato A. The paradox of the Lupus anticoagulant: history and perspectives. Semin Thromb Hemost 2014;40(8):860-865

14 Favaloro EJ, Wong RC. Antiphospholipid antibody testing for the antiphospholipid syndrome: a comprehensive practical review including a synopsis of challenges and recent guidelines. Pathology 2014;46(6):481-495 
15 Triplett DA. Laboratory diagnosis of lupus anticoagulants. Semin Thromb Hemost 1990;16(2):182-192

16 Douglas A. Triplett Obituary. Available at: http://www.legacy. com/obituaries/jconline/obituary.aspx?pid=164404186. Accessed August 30, 2014

17 Wada H, Matsumoto M, Yamashita Y. Natural history of thrombotic thrombocytopenic purpura and hemolytic uremic syndrome. Semin Thromb Hemost 2014;40(8):866-873

18 Favaloro EJ. Hemolytic uremic syndrome. Preface. Semin Thromb Hemost 2010;36(6):573-574

19 Riedl M, Orth-Höller D, Würzner R. An update on the thrombotic microangiopathies hemolytic uremic syndrome (HUS) and thrombotic thrombocytopenic purpura (TTP). Semin Thromb Hemost 2014;40(4):413-415

20 Levi M, van der Poll T. A short contemporary history of disseminated intravascular coagulation. Semin Thromb Hemost 2014; 40(8):874-880
21 Bick RL. Disseminated intravascular coagulation and related syndromes: a clinical review. Semin Thromb Hemost 1988;14(4): 299-338

22 Franchini M, Lippi G, Favaloro EJ. Dedication. Rodger L. Bick, M.D., Ph.D., FACP (1943-2008). Semin Thromb Hemost 2009;35: 255-256

23 Fareed J, Walenga J, Messmore H, Baker W, Bick M. In memoriam: Rodger L. Bick, MD, PhD, FACP-a wonderful friend, great clinician, and brilliant educator. Clin Appl Thromb Hemost 2009; $15: 5-7$

24 Ellery PER, Adams MJ. Tissue factor pathway inhibitor: then and now. Semin Thromb Hemost 2014;40(8):881-886

25 de Maat S, de Groot PG, Maas C. Contact system activation on endothelial cells. Semin Thromb Hemost 2014;40(8):887-894

26 Oldenburg J, Pezeshkpoor B, Pavlova A. A historic review on genetic analysis in hemophilia A. Semin Thromb Hemost 2014; 40(8):895-902 